\title{
CONSULTORIA EMPRESARIAL: UMA OPÇÃO DE CARREIRA PARA O SECRETÁRIO EXECUTIVO?
}

\section{BUSINESS CONSULTING: A CAREER OPTION FOR THE EXECUTIVE SECRETARY?}

\section{Sonia Regina Amorim Soares de Alcântara}

Mestre em Administração de Empresas. Professora do Departamento de Administração da Universidade Federal do Ceará (UFC). E-mail: reginasoaresm@gmail.com (Brasil)

\author{
Washington Carlos Ribeiro Pereira \\ Bacharel em Secretariado Executivo pela Universidade Federal do Ceará (UFC). E-mail: \\ mrwcrp@gmail.com (Brasil)
}




\title{
CONSULTORIA EMPRESARIAL: UMA OPÇÃO DE CARREIRA PARA O SECRETÁRIO EXECUTIVO?
}

\section{RESUMO}

A consultoria e o perfil do Secretário Executivo (SE) estão sendo estudados pela literatura acadêmica recente, sobre a oportunidade de este profissional atuar como consultor. Esta pesquisa busca verificar se o SE considera a consultoria empresarial uma opção de carreira. Os objetivos específicos são: a) levantar a percepção dos professores, estudantes e egressos do curso de Secretariado Executivo da UFC acerca da consultoria como opção de carreira; b) identificar se há o interesse dos estudantes e egressos deste curso na carreira de consultor; c) analisar a formação necessária para um consultor e comparar com a formação oferecida ao SE. Para isso, discute-se o mercado de consultoria, o perfil do consultor e do SE e suas competências. Este trabalho é uma pesquisa de campo, qualitativa e descritiva, com dados coletados por meio de questionário, utilizando a análise de conteúdo para a interpretação dos dados. Constatou-se que a maioria dos sujeitos considera que o SE está apto a seguir carreira em consultoria, especialmente em desenvolvimento organizacional, gestão de pessoas, processos e estratégia, entretanto o interesse dos estudantes e egressos nessa carreira ainda é mínimo. Infere-se que este achado decorre do reduzido estímulo oferecido e o contato incipiente com consultoria durante a graduação. O perfil do SE se aproxima ao do consultor pelas competências que mais são desenvolvidas naquele durante a graduação. Conclui-se que a consultoria é uma área promissora para o SE; porém é necessária formação complementar.

Palavras-chave: Consultoria Empresarial. Secretariado Executivo. Competência profissional.

\section{BUSINESS CONSULTING: A CAREER OPTION FOR THE EXECUTIVE SECRETARY?}

\begin{abstract}
The consulting and the profile of the Executive Secretary (ES) are being studied by the recent academic literature, analyzing the opportunity of this professional to act as a consultant. This research aims to verify if the ES considers business consulting as a career option. The specific objectives are: a) to find out the perception of teachers, students and graduates of the Executive Secretariat course of UFC about consulting as a career option; b) identify if there is the interest of the students and graduates in the consultant career; c) analyze the formation required for a consultant and compare it with the formation given to the ES. Therefore, the consulting market, the consultant's and the ES's profile and their competences are discussed. This work is a qualitative and descriptive field research, with data collected through a questionnaire. Content analysis was used to interpret the data. It was found that the majority of the subjects consider that the ES is able to build a career in consulting, especially in organizational development, human resources, processes and strategy, however the interest of the students and graduates in this career is still minimum. It is inferred that these results are due the reduced stimulus offered and the incipient contact with consulting during the undergraduate course. The ES's profile goes towards consulting by the most developed competences in the first one. In conclusion, consulting is a promising career for the ES, but complementary formation is required.
\end{abstract}

Keywords: Business Consulting. Executive secretariat. Professional skills. 


\section{INTRODUÇÃO}

Nos últimos 20 anos, o perfil das organizações em todo o mundo tem se modificado intensamente. $O$ processo de globalização afetou a forma como as empresas atuam no mercado. No Brasil, esse processo teve um crescimento maior principalmente após as décadas de 1980 e 1990, quando o país passou a adotar políticas mais liberalistas, permitindo que grandes empresas adentrassem ao território nacional com mais intensidade (Coelho, 2013). Quanto aos negócios locais, esse fenômeno da globalização foi decisivo para a mudança em sua forma de atuação. Desde então a competitividade no mercado só aumentou. E para lidar com essa competitividade atual, as organizações precisam estar sempre à frente da concorrência, buscando maximizar sua participação no mercado e consolidar sua marca na mente do consumidor (Coelho, 2013). É nesse contexto que a consultoria empresarial ganha destaque. Esta, ao longo das últimas décadas, vem auxiliando milhares de empresas no mundo todo a superar os desafios da globalização da economia.

Concomitante ao processo de desenvolvimento da consultoria empresarial no Brasil, a partir da segunda metade do século passado, a profissão de Secretário Executivo vem ganhando cada vez mais espaço no contexto organizacional. Mostrando um crescimento exponencial e buscando cada vez mais acompanhar as frequentes mudanças do ambiente econômico globalizado, o profissional dessa área agregou compulsoriamente responsabilidades e atribuições de outras áreas administrativas, o que desenvolveu consequentemente um novo perfil demandado para a profissão. "Com o passar dos anos, o secretário passou a se aprimorar como assessor e, consequentemente, a desempenhar outras funções, que a princípio, eram de responsabilidades dos executivos tais como: cogestão, consultoria e empreendedorismo" (Paes, Antunes, Santiago \& Zwierzikowski, 2015, p. 102, grifo nosso). A partir dessas novas competências no perfil do SE, a consultoria empresarial vem sendo discutida como uma alternativa de atuação para o secretário executivo, inclusive pelas próprias Diretrizes Curriculares Nacionais para o curso de Secretariado Executivo (Brasil, 2005). Por isso, este trabalho busca responder ao seguinte questionamento: $o$ Secretário Executivo considera a consultoria empresarial como opção de carreira?

Para responder a essa questão, optou-se por realizar um estudo de campo, sob a perspectiva de diferentes sujeitos, a saber, professores, estudantes e egressos do curso de Secretariado Executivo da Universidade Federal do Ceará (UFC), ambiente selecionado para a condução da pesquisa. O principal objetivo do presente trabalho é verificar se o profissional de Secretariado Executivo considera a consultoria empresarial como opção de carreira. Como objetivos específicos, foram definidos: a) levantar a percepção dos professores, estudantes e egressos do curso de Secretariado Executivo da UFC acerca da consultoria como opção de carreira; b) identificar se há o interesse dos estudantes e egressos deste curso em seguir carreira na área de consultoria empresarial; e c) analisar a formação necessária para um consultor e comparar com a formação dada ao estudante de Secretariado Executivo.

Justifica-se este estudo pelas discussões travadas nos últimos anos sobre a possibilidade de carreira na área de consultoria empresarial para o profissional de secretariado, contudo, ainda são poucas as pesquisas publicadas acerca do tema, e as publicações feitas até então carecem de aprofundamento. Logo, busca-se com este trabalho ampliar a discussão e gerar conhecimento por meio do levantamento das percepções dos discentes, egressos e docentes do curso de Secretariado Executivo da UFC, da análise da formação acadêmica nesse curso e da reflexão crítica sobre a possibilidade de seguir a carreira de consultor.

Este artigo esta subdividido em seis partes, sendo a primeira esta introdução, seguida pelo referencial teórico, que se subdivide em duas partes: a consultoria empresarial e as competências do profissional de Secretariado Executivo. Em seguida são apresentados a 
metodologia e os resultados, segmentados em formação do profissional de secretariado, formação técnica e comportamental para consultoria e a carreira de consultor. Por fim, são apresentadas as considerações finais e as referências do estudo.

\section{CONSULTORIA EMPRESARIAL: CONCEITOS E ATUAÇÃO PROFISSIONAL}

A seguir serão apresentados os principais conceitos relacionados à consultoria empresarial. Por ser um termo abrangente, cabe explicitar a definição e apresentar os principais aspectos relacionados ao conceito propriamente dito, à profissão de consultor e ao mercado de consultoria no Brasil e no mundo.

\subsection{Consultoria empresarial}

Para se conhecer os aspectos que envolvem a consultoria empresarial, é necessário primeiramente apresentar alguns conceitos sobre essa área. Neste trabalho destacam-se os conceitos de Crocco e Guttmann (2010), Oliveira (2012), Block (2011) e Schein (2008), entretanto é possível encontrar na literatura acadêmica diversos autores que conceituam o tema, sob diferentes perspectivas. Crocco e Guttmann (2010, p. 8), destacam que:

Consultoria é um processo interativo, executado por uma ou mais pessoas, independentes e externas ao problema em análise, com o objetivo de fornecer aos executivos da empresa-cliente um ou mais conjuntos de opções de mudanças que proporcionem a tomada de decisão mais adequada ao atendimento das necessidades da organização.

Semelhante a esta definição, Oliveira (2012, p. 4) afirma que a consultoria empresarial "é um processo interativo de um agente de mudanças externo à empresa, o qual assume a responsabilidade de auxiliar os executivos e profissionais da referida empresa nas tomadas de decisões, não tendo, entretanto, o controle direto da situação". Ao observar os dois conceitos, percebe-se que os autores têm uma visão parecida acerca do tema. É possível visualizar isso também ao analisar o termo consultor, na concepção de Block (2011, p. 2) "A consultant is a person in a position to have some influence over na individual, a group, or an organization but has no direct power to make changes or implement programs", ou seja, em tradução nossa, "um consultor é uma pessoa em posição de influência sobre um indivíduo, um grupo ou uma organização, mas que não tem poder direto para fazer mudanças ou implementar programas". Um aspecto relevante para análise está relacionado às características fundamentais da consultoria, que é a recomendação e o auxilio, ou como conceitua Schein (2008), o processo de ajuda. Sobre esse aspecto, Crocco e Guttmann (2010) defendem que o que se espera de um consultor é o aconselhamento, não a decisão, e isso implica não ter controle direto sobre a situação ou sobre a decisão. "A responsabilidade de aconselhar existe, mas a autoridade ou a liberdade de decisão não" (Crocco \& Guttmann, 2010, p. 8).

Alternativamente aos conceitos mais utilizados na literatura acadêmica nacional, Schein (2008) defende um conceito de consultoria específico, fundamentado nos processos sociais e psicológicos por trás da relação de ajuda, a Consultoria de Processos (CP). Segundo o autor, "todas as formas de consultoria implicam a ajuda de uma pessoa a outra, daí o foco central nesta análise ser decifrar o que é útil e o que não é numa dada situação humana" (Schein, 2008, p. 23). O autor define consultoria de processos como: "a criação de uma relação com o cliente que permita a ele perceber, entender e agir sobre acontecimentos progressivos que ocorrem no seu ambiente interno e externo de modo a melhorar a situação tal como definida por esse cliente" (Schein, 2008, p. 41).

Schein (2008) apresenta dois modelos consolidados de consultoria, baseados nos diferentes papéis que o consultor pode assumir no processo de consultoria, ou seja, nos 
diferentes modos de atuar. O primeiro modelo é o da Compra de Informação ou Modelo Especialista. Tal modelo pressupõe que o cliente tem determinada necessidade e não dispõe de tempo e recursos suficientes para atender a essa necessidade, sendo então contratado um especialista para prestar essa informação ou serviço, como no caso de uma análise mercadológica para identificar a estratégia de marketing de um concorrente, por exemplo. Segundo o autor, para que este modelo funcione, é necessário que o cliente tenha claro que tipo de necessidade exata ele possui, ou seja, que ele tenha feito um diagnóstico correto e que tenha comunicado isso claramente ao consultor. O outro modelo é o do Médico-Paciente (Schein, 2008). Neste modelo o cliente sente que algo não vai bem na organização ou deseja saber se existe alguma área que requeira maior atenção ou que não esteja funcionando adequadamente. Então o consultor é chamado para fazer um exame geral na organização. "O consultor é trazido à organização para descobrir o que está errado e em qual parte da organização e, então, como um médico, espera-se que recomende um programa de tratamento ou prescreva uma medida capaz de remediar a situação" (Schein, 2008, p. 32).

A alternativa da CP está fundamentada na premissa de que "o consultor nunca sabe o suficiente sobre a situação particular e sobre a cultura da organização para ser capaz de fazer recomendações específicas sobre o que os membros dessa organização deveriam fazer para resolver os seus problemas" (Schein, 2008, p. 21). Nessa alternativa, ao ajudar o cliente a resolver os problemas da sua organização e não simplesmente resolvê-los por si só, partindo do pressuposto de que se sabe exatamente a solução ideal para o problema, o consultor está desenvolvendo dentro do sistema cliente a capacidade de aprender a lidar com sua realidade e a gerir as mudanças organizacionais presentes e futuras. Como o cliente está envolvido durante todo o processo da consultoria, as possibilidades de resistência ao diagnóstico e implementação das sugestões de melhoria/mudança são extremamente baixas, uma vez que o cliente é o principal responsável pelo que está sendo sugerido e é o único na relação que conhece em profundidade a realidade da organização, sua cultura, políticas e procedimentos. Dessa forma, as chances de sucesso são maiores, pois o nível de engajamento que o cliente terá com o projeto será maior do que quando adotadas outras formas de atuação na consultoria.

\subsection{Tipos de consultoria empresarial e atuação do consultor}

Conhecer os tipos de consultoria, de acordo com Crocco e Guttmann (2010), é necessário para um bom relacionamento entre consultor e empresa-cliente. É indispensável tanto para o consultor, pois assim tem condições de definir claramente seu diferencial competitivo no mercado, quanto para o cliente, que pode entender melhor que tipos de intervenção serão feitos em sua empresa e se suas necessidades legítimas serão atendidas. Dessa forma, é possível classificar, de maneira não exaustiva, a consultoria segundo alguns tipos. Seguindo os conceitos de Crocco e Guttmann (2010), é viável fazer essa classificação de acordo com três critérios: a estrutura, a abrangência e a forma de relacionamento.

Quanto à estrutura, classifica-se em consultoria artesanal e consultoria de pacote. A primeira busca adaptar as metodologias e técnicas administrativas a serem empregadas na empresa-cliente de acordo com sua realidade. Portanto, o projeto é desenvolvido com características exclusivas para cada cliente, tendo, embora, embasamento em outras abordagens e modelos já aplicados em outras empresas. Já a consultoria de pacote adota metodologias e técnicas específicas, genéricas e abrangentes, que servem para diversas situações de diversas empresas, buscando atender as necessidades do cliente com base em soluções predefinidas. "O nível de flexibilidade é reduzido, ou seja, existe uma alta dose de rigidez nessa estrutura, pois o consultor se utiliza de metodologia quase fechada com base em conceitos reconhecidos e práticas testadas" (Crocco \& Guttmann, 2010, p. 71). 
Quanto à abrangência, classifica-se em consultoria especializada e consultoria total. A primeira caracteriza-se por sua atuação focada, por ter produtos que atuam em áreas de conhecimento específicas e somente nessas áreas. A consultoria total caracteriza-se por ter produtos de diferentes áreas do conhecimento e por atuar em praticamente todas as áreas e processos da empresa-cliente. "Nesse caso, o consultor tem alguns produtos e também conhece outros consultores que podem complementar a abrangência para que seu profissionalismo não seja questionado e exista integração de produtos e consultores" (Crocco \& Guttmann, 2010, p. 75).

Por último, é possível definir o tipo de consultoria de acordo com a forma com que o consultor se relaciona com seu cliente e com seus parceiros. Assim, os mesmos autores apresentam três tipos de relacionamento que influenciam diretamente na forma como a consultoria é ofertada. O primeiro tipo pode ser definido pela busca de uma parceria para a oferta do produto da consultoria, sendo feita entre pessoas físicas, pessoa física e pessoa jurídica e/ou entre pessoas jurídicas - trata-se do consultor associado. O segundo tipo é o consultor autônomo, pessoa física atuando por conta própria. Este caracteriza-se por prestar um serviço de forma independente, ou seja, não está necessariamente associado a uma empresa para a oferta do produto da consultoria. E por último, tem-se o consultor virtual, que atua a distância, ou seja, ele desenvolve todo o trabalho da consultoria de forma remota, seu relacionamento com o cliente se dá por meio de correspondência em papel, eletrônica ou telefônica (Crocco \& Guttmann, 2010).

Segundo Coelho (2013), os objetivos da consultoria são: alcançar as metas e os objetivos da organização, solucionar problemas gerenciais e empresariais, identificar e avaliar novas oportunidades, gerar capacitação e aprendizagem e gerar mudanças. Para atender a essas necessidades, o consultor precisa contar com sólidos conhecimentos e experiências em diversas áreas, mas deve, essencialmente, ser especialista em sua área de atuação. Este profissional "deve ter sólida cultura geral, interesses e experiências diversificadas, embora com especialização quanto ao serviço oferecido e realizado nas empresas-clientes" (Oliveira, 2012, p. 160). Os resultados da pesquisa do perfil das empresas de consultoria do Brasil 2014, publicada pelo Laboratório da Consultoria (2015), reforçam essa ideia. Segundo os respondentes, as empresas-clientes consideram mais importantes em um consultor os atributos conhecimento $(84,3 \%)$ e experiência $(83,9 \%)$. Oliveira (2012, p. 175) destaca ainda que:

O consultor empres arial deve ser generalista, pois suas propostas são, naturalmente, interagentes com outras atividades da empresa-cliente. E tem que ser especialis ta, porque é obrigado a ter elevado conhecimento a respeito de metodologias e técnicas inerentes ao foco de sua consultoria.

Assim, para o profissional que trabalha ou deseja trabalhar na área de consultoria empresarial, é essencial saber encontrar um equilibrio entre o perfil de atuação generalista, que tem uma visão holística da organização e com domínio de conhecimentos diversos; e o especialista, com sólidos conhecimentos e experiências em uma área específica de atuação. Para seguir carreira em consultoria empresarial, o profissional precisa estar atento aos diversos aspectos relativos a esta profissão. O plano de carreira para atuar na profissão de consultor empresarial, segundo Oliveira (2012) está embasado no tripé: sustentação conceitual, experiência com foco de atuação e publicações com apresentações.

A sustentação conceitual refere-se essencialmente à formação do profissional, que deve ser composta por um bom curso de graduação e, preferencialmente, por um curso de pós-graduação na área de atuação em consultoria. $\mathrm{O}$ segundo item do tripé está fundamentado em uma larga experiência profissional, com direcionamento para uma área específica, na qual o consultor tem um produto específico a oferecer no mercado. "O terceiro item do tripé é representado pelas publicações do consultor, evidenciadas por artigos, pareceres e livros, bem 
como as correspondentes apresentações por meio de seminários, palestras e treinamentos em geral" (Oliveira, 2012, p. 33). Dessa forma, para ser um bom profissional em consultoria empresarial, é importante estar atento aos três itens do tripé e, além disso, buscar saber se o seu perfil profissional está alinhado ao perfil de um consultor. Igualmente importante para a atuação profissional de um consultor é entender quais os conhecimentos, habilidades e atitudes requeridas para um bom desempenho no trabalho de consultoria.

É possível segmentar as habilidades inerentes à consultoria empresarial em três grupos, de acordo com os conceitos de Block (2011). Estes são compostos por habilidades técnicas, interpessoais e consultivas. Segundo o autor, as habilidades técnicas se referem à experiência do consultor em determinado campo de atuação, como marketing, planejamento, engenharia, finanças, gestão de projetos etc. Como a consultoria é mantida essencialmente por um relacionamento entre consultor e cliente, as habilidades interpessoais são igualmente importantes para a atuação do profissional, que para Block $(2011$, p. 5) são "[...] ability to put ideas into words, to listen, to give support, to disagree reasonably, to basically maintain a relationship.", e, segundo nossa tradução, "[...] habilidades de transformar ideias em palavras, de ouvir, de prestar apoio, de discordar de forma sensata, de basicamente manter um relacionamento". Por fim, as habilidades consultivas, segundo o autor, se referem à obediência dos cinco passos básicos de qualquer projeto de consultoria, que são: entrada e contrato; descoberta e diálogo; análise e decisão para agir; compromisso e implementação; e extensão, reciclagem ou término.

Ainda sobre esse aspecto, Oliveira (2012) argumenta que o produto ou serviço que um consultor oferece no mercado contempla três componentes: a) a especialidade que está sendo oferecida, tais como planejamento estratégico, estrutura organizacional, reengenharia, sistema de informações gerenciais, engenharia simultânea, pesquisa de mercado etc.; b) a competência e o nível de conhecimento do consultor no assunto considerado; e c) a amplitude e o estilo de atuação do consultor, tendo em vista a melhor interação com a realidade da empresa-cliente.

Dessa forma, a partir do entendimento dos principais conceitos, dos tipos de consultoria empresarial, além da atuação profissional do consultor e suas competências, tornase relevante entender como se comporta o mercado de consultoria no Brasil e no mundo.

\subsection{Mercado de consultoria empresarial}

A consultoria começou a ganhar destaque no âmbito empresarial a partir da segunda metade do século XX, principalmente após os anos de 1980, quando as empresas passaram a modificar suas estruturas organizacionais, pautadas em revoluções que ocorriam no mercado na época, devido, principalmente, ao fenômeno da globalização dos mercados. Tendências como incorporação das práticas de gestão japonesas, enfoque na Qualidade Total, busca por obtenção de certificações de qualidade em processos de gestão e produção, incorporação da tecnologia da informação às ferramentas gerenciais das organizações, bem como os fenômenos de reengenharia e downsizing abriram espaços para a atuação mais forte das empresas de consultoria no mundo todo, especialmente nos Estados Unidos (Donadone \& Sznelwar, 2004).

Quanto ao mercado de consultoria no Brasil, segundo Coelho (2013), as primeiras empresas de consultoria começaram a chegar ao país a partir da década de 1970, provenientes principalmente dos Estados Unidos. 'Não existia, até então, a cultura empresarial de contratar agentes externos para auxiliar na melhoria dos processos e por consequência no crescimento da lucratividade das empresas" (Coelho, 2013, p. 1). A partir de então, esse mercado cresceu em âmbito nacional. Na década de 1990, houve a abertura do mercado no governo Collor de Mello, inserindo definitivamente o Brasil no mundo globalizado, levando as empresas a 
buscarem as melhores práticas empresariais com foco na melhoria da produtividade e, como consequência, adquirir vantagens competitivas perante seus concorrentes (Coelho, 2013).

Em relação ao cenário atual, Oliveira (2012) afirma que apesar das dificuldades de se mensurar o tamanho da indústria de consultoria, é possível considerar que existem cerca de 900 empresas de grande porte no mundo e que 70\% do mercado total de serviços de consultoria são comandados por aproximadamente 50 empresas. Quanto ao faturamento anual, analisando uma perspectiva histórica, percebe-se que esse mercado começou a alavancar de verdade a partir da década de 1980.

O cenário do mercado de consultoria no Brasil hoje se mostra cada vez mais promissor. Segundo pesquisa realizada em 2014 e publicada pelo Laboratório da Consultoria (2015) em parceria com a Associação Brasileira de Consultores (ABCO), 75,7\% das empresas de consultoria no Brasil são de pequeno porte, com faturamento médio anual de até 500 mil reais, sendo compostas em sua maioria $(80 \%)$ por até cinco consultores, concentradas principalmente nas regiões Sudeste $(65,1 \%)$ e Sul $(21,6 \%)$, estando apenas $4,7 \%$ delas situadas na região Nordeste. Um dado relevante é que em $75,7 \%$ dessas empresas os consultores podem se tornar sócios dessas consultorias nas quais prestam serviços, fator que pode estimular cada vez mais profissionais a ingressarem nessa carreira. Em consonância com esses dados, segundo Oliveira (2012, p. 16), "uma pesquisa realizada pela Universidade de Harvard mostrou que a maioria das empresas de consultoria é pequena, faturando abaixo de US\$ 500.000,00/ano e com uma equipe de quatro consultores". Portanto, o faturamento médio anual das consultorias norte-americanas é estimado em cerca de 3,5 vezes maior que o das consultorias brasileiras, conforme esclarecido acima.

No mesmo contexto de ascensão do mercado de consultoria no Brasil, a partir da segunda metade do século XX, a profissão de Secretário Executivo também começou a conquistar mais espaço profissional e o perfil atual do secretário vem ao encontro dessa tendência. "Acompanhando a crescente do mercado secretarial é essencial que o recémformado e até mesmo o profissional que busca uma recolocação conheça quais são as novas áreas em que encontrará oportunidades" (Paes et al., 2015, p. 103). Estar atento às oportunidades de carreira é fundamental para quem busca sucesso profissional.

\subsection{Secretariado executivo: competências profissionais}

A partir das concepções expostas nas seções anteriores, é possível aprofundar a análise considerando o profissional de Secretariado e sua relação com a consultoria empresarial. Portanto, a seguir, serão apresentadas discussões acerca da atuação do Secretário Executivo enquanto consultor empresarial, englobando também uma abordagem de suas competências profissionais.

\subsection{Secretariado executivo e o contexto profissional}

Para entender o contexto atual da profissão de Secretário Executivo, bem como as competências agregadas ao perfil do profissional, é relevante analisar a evolução histórica dessa área. Resumidamente, foram várias as conquistas que essa profissão alcançou nas últimas décadas, dentre elas é possível mencionar a criação do primeiro curso de bacharelado na Universidade Federal da Bahia em 1969, a regulamentação da profissão pelas Leis 7.377/85 e 9.261/96, criação da Federação Nacional das Secretárias e Secretários (Fenassec) em 1988, do Código de Ética do Profissional em 1989 entre outras, impulsionando o Secretariado enquanto profissão. No entanto, foi a partir da década de 1990 que se teve um maior fortalecimento da área no âmbito acadêmico, uma vez que surgiram diversos cursos de graduação em universidades do país (Nonato Júnior, 2009). A partir daí, consolidavam-se as 
bases legais e estruturais para a ascensão da profissão, bem como para o desenvolvimento do profissional.

As constantes revoluções causadas pela globalização da economia no ambiente empresarial e a necessidade preeminente de profissionais capacitados, com múltiplas habilidades e formação consolidada foram fatores que estimularam a ascensão do profissional de Secretariado Executivo no mercado de trabalho. Para atender às novas e cada vez mais dinâmicas demandas das organizações, o profissional de Secretariado entra no século XXI com um perfil de atuação bem diferente do anterior, como salientado no texto de Martins, Terra, Maccari e Vicente (2010, p. 3): "as pessoas que atuam nessa área deixaram de ser apenas apoio, e passaram a ser consideradas como complementação do trabalho dos executivos, que delegam cada vez mais tarefas, pela qualificação que os profissionais da área vêm apresentando a cada dia". Com mais responsabilidades sendo agregadas constantemente ao seu campo de atuação, este profissional precisa contar com uma formação consolidada, essencialmente um bom curso de graduação e, de preferência, alguma pós-graduação. Assim, a formação que o profissional adquire impacta diretamente na sua atuação no mercado e no seu sucesso profissional. Silva (2010, p. 5, grifo nosso) reforça a relevância dessa formação, ao citar que:

[...] a visão atual das atribuições deste profissional está em atender as expectativas de trabalho não só dos executivos, mas, também, das organizações, com autonomia de gestão, assessoria, gerenciamento e consultoria. Essa visão é construída com competências que são transmitidas nas IES e obtidas durante as experiências vivenciadas.

Portanto, é essencial que as Instituições de Ensino Superior (IES) que ofertam o curso de Secretariado Executivo estejam atentas às mudanças que ocorrem constantemente no mercado e no campo de atuação do profissional de Secretariado para que preparem adequadamente os graduandos dessa área. Exemplo disso é a identificação nos últimos anos da possibilidade de atuação desse profissional em diversas áreas antes não exploradas pelo Secretariado, isso principalmente pela sua formação generalista e multidisciplinar -, é o caso da consultoria empresarial.

Essas constantes mudanças causadas pela globalização dos mercados fizeram com que o profissional de Secretariado adaptasse sua forma de atuação para não se tornar obsoleto, sendo essa adaptação uma de suas principais características. Dessa forma, esse profissional deixou de apenas executar para delegar tarefas, gerenciar processos, informações, pessoas, atuando de forma cada vez mais estratégica na organização, assemelhando-se muito ao perfil de um consultor (Adelino \& Silva, 2012; Paes et al., 2015; Silva, 2010).

Com isso, alguns autores, como Martins, Terra, Kiehn e Kniess (2015); Paes et al. (2015); Schmitz, Battisti e Santos (2015); Silva (2010) entre outros, defendem que pela evolução do campo de atuação, bem como pela formação generalista e multidisciplinar que o Secretariado tem adquirido nas últimas décadas, o profissional dessa área está apto a ingressar na carreira de consultor. Paes et al. (2015, p. 117) argumentam que "o perfil profissional de um consultor assemelha-se muito ao perfil profissional do secretário, e sua formação permite a atuação como consultor secretarial interno e externo".

As Diretrizes Curriculares Nacionais (DCN) (Brasil, 2005) para o curso de Secretariado Executivo, que instituem as bases para a estruturação dos cursos de graduação nessa área no Brasil, também abordam a consultoria como opção de atuação para os profissionais desse curso. $\mathrm{O}$ Artigo $2^{\circ}$, parágrafo segundo deste documento aponta que:

Os projetos pedagógicos do curso de graduação em Secretariado Executivo poderão admitir linhas de formação específicas, nas diversas áreas relacionadas com atividades gerenciais, de assessoramento, de empreendedorismo e de consultoria, contidas no exercício das funções de Secretário Executivo, para melhor atender às 
necessidades do perfil profissiográfico que o mercado ou a região exigirem (Brasil, 2005, p. 2, grifo nosso).

Devido à abrangência do perfil profissional no Secretariado Executivo, o atual cenário das organizações e sua necessidade de buscar competitividade e consolidar cada vez mais participação de mercado, Schmitz et al. (2015, p. 31) argumentam que:

[...] percebe-se que há uma convergência entre a exigência do mercado e a polivalência do profissional de Secretariado Executivo e as diretrizes traçadas para a formação acadêmica, inclusive prevendo a atividade de consultoria como função. Essa convergência é fundamental para que se avance na introdução do profissional nesse mercado específico da consultoria empresarial.

Entretanto, as mesmas autoras afirmam que "embora esse profissional seja visto como um ser dinâmico e versátil, ou seja, um profissional que se sobressai em diversos setores abrangentes ao seu perfil, ainda é pouco associado ao serviço de consultoria" (Schmitz et al. 2015 , p. 22). Portanto, é relevante estudar melhor este mercado, verificar a qualidade da formação dada aos profissionais secretários, além das competências necessárias para exercer a profissão para que se possa avaliar de maneira assertiva suas possibilidades de ingresso e atuação em consultoria empresarial.

\subsection{Competências do profissional de Secretariado Executivo}

Em relação às competências profissionais, é possível verificar essa polivalência do perfil secretarial ao analisar os estudos de Durante (2012) sobre o tema. Segundo a autora, competência representa um conjunto de conhecimentos, habilidades e atitudes que agregam valor tanto à organização quanto ao próprio indivíduo. Durante (2012, p. 28) ressalta que a competência é composta por um conjunto de diferentes saberes: '[...] saber, saber fazer e saber ser, de tal modo que competência e aprendizagem estão conectadas, servindo-se uma da outra. Uma competência demanda novas aprendizagens, assim como a aprendizagem pode levar a uma nova competência". A autora classifica as competências do profissional de Secretariado Executivo em três categorias, a saber, técnicas, analíticas e de ação e comportamentais e relacionais.

As competências de ordem técnica estão relacionadas ao saber fazer, ao cerne da profissão. Nessa categoria constam as técnicas secretariais, que podem ser entendidas como os conhecimentos elementares do fazer secretarial, o uso de tecnologias, competência indispensável para o gerenciamento de informações e auxílio na tomada de decisões e o domínio de idiomas estrangeiros, igualmente importante para a atuação do profissional, principalmente pela internacionalização crescente das empresas (Durante, 2012).

As competências analíticas e de ação, segundo Durante (2012), estão relacionadas com a gestão das organizações. Por meio dessas competências o profissional consegue atuar de maneira mais efetiva, uma vez que tem um conhecimento e visão do todo da organização (visão sistêmica), o que possibilita analisar e gerenciar os impactos de decisões em diferentes setores e grupos. Organização, estratégia, planejamento e controle dizem respeito ao entendimento do ambiente interno e externo da organização e ao emprego de ações específicas direcionadas ao alinhamento com os objetivos, estratégia, cultura, estrutura, processos entre outros aspectos que guiam a essência do negócio. Neiva e D’Elia (2009, p. 31) reforçam essa ideia ao expressar que "[...] o secretário está inserido no processo gerencial das empresas, como um profissional vital, para trabalhar ao lado do poder decisório, otimizando resultados em times, virtualmente e nas múltiplas opções que o mercado de trabalho oferece a todos os profissionais".

Por último, as competências comportamentais e relacionais, para Durante (2012), estão atreladas ao saber ser e se relacionar com os outros no ambiente de trabalho, aspecto 
inerente às relações humanas. Comunicação, relação interpessoal e trabalho em equipe são indispensáveis à atuação profissional, uma vez que o ambiente organizacional está cada vez mais multidisciplinar e multicultural, no qual o trabalho colaborativo impera, o fluxo de informações é constante e a necessidade de alinhamento é crucial para o bom desempenho tanto da organização quanto do profissional, uma vez que este atua como elo de ligação entre diversas instâncias. "Para atuar como agente facilitador, uma das competências mais importantes para o profissional secretário é a comunicação" (Neiva \& D’Elia, 2009, p. 89). Igualmente importante para um bom desempenho, criatividade, ética, flexibilidade, liderança e negociação cooperam para a plenitude do perfil secretarial.

Esse conjunto de conhecimentos, habilidades e atitudes, conclui Durante (2012), são complementares e podem se manifestar em maior ou menor grau em cada indivíduo, a depender de sua área de atuação ou posição dentro da organização. Então para um profissional que atue na gestão de equipes, por exemplo, o trabalho em equipe e a liderança são consideradas competências principais. Dessa forma, essa gama de competências inerentes ao profissional de secretariado de hoje, ilustram essa mudança do perfil operacional do século passado para esse novo perfil gerencial. No entanto, a autora alerta que "é necessário [...] que o secretário se posicione de maneira que a organização perceba o seu potencial" (Durante, 2012, p. 38). Outro aspecto a considerar é a necessidade da busca contínua por aprendizagem, pelo saber, saber fazer e saber ser, a fim de manter ativo o processo de formação do ser humano.

\section{METODOLOGIA}

Este trabalho caracteriza-se como sendo uma pesquisa de campo, pois "[...] baseia-se na observação dos fatos tal como ocorrem na realidade" (Andrade, 2010, p. 113). Apesar de parte dos dados ser apresentada numericamente, a pesquisa é qualitativa, pois se preocupa principalmente com a descrição, compreensão e interpretação dos fatos ao invés de medições (Martins \& Theóphilo, 2009; Rodrigues, 2006). É descritiva, pois segundo Andrade (2009, p. 114), "[...] nesse tipo de pesquisa, os fatos são observados, registrados, analisados, classificados e interpretados, sem que o pesquisador interfira neles".

Para a coleta dos dados foi aplicado um modelo de questionário para todos os sujeitos da pesquisa, com diferenciação de duas questões. Para Marconi e Lakatos (2010, p. 184), "questionário é um instrumento de coleta de dados, constituído por uma série ordenada de perguntas, que devem ser respondidas por escrito e sem a presença do entrevistador". Este, é composto por 12 questões, abertas e fechadas, havendo personalização das duas últimas para os diferentes sujeitos. Dessa forma, duas perguntas são direcionadas apenas para professores e duas perguntas direcionadas somente para estudantes e egressos do curso. Nestas foi questionado para os professores acerca da atratividade do mercado de consultoria no Ceará para o profissional de secretariado e para os estudantes e egressos se havia pretensão de atuar como consultor e se se sentiram estimulados a aprofundar seus conhecimentos na área de consultoria. O questionário foi aplicado por e-mail, por meio da ferramenta Google Forms.

Para a definição dos sujeitos da pesquisa e da amostra foram considerados critérios de acessibilidade, uma vez que não seria possível alcançar todos os sujeitos. "A amostra é uma parcela convenientemente selecionada do universo (população); é um subconjunto do universo" (Marconi \& Lakatos, 2003, p. 163). Essa amostra foi alcançada por meio de uma listagem com nomes e e-mails dos sujeitos da pesquisa, cedida pela coordenação do curso de Secretariado Executivo da UFC. A pesquisa foi desenvolvida com três tipos de sujeitos: professores, estudantes e egressos do curso de Secretariado Executivo da UFC, sendo considerada a realidade do período letivo de 2016.1. Neste período funcionam regularmente 
os semestres $1^{\circ}, 3^{\circ}, 5^{\circ}, 7^{\circ}$ e $9^{\circ}$ do curso. A partir disso, foram definidos os seguintes critérios para selecionar a amostra a ser pesquisada:

a) Professores - Todos os sete professores titulares, que ministram aulas no curso, atualmente graduados e/ou pós-graduados nas áreas de Secretariado Executivo e/ou Administração;

b) Alunos - Os 67 estudantes regularmente matriculados nos semestres $5^{\circ}, 7^{\circ}$ e $9^{\circ}$, portanto com uma carga horária cumprida acima de $45 \%$ do total, que lhes confere mais tempo de curso e assim maior maturidade sobre o Secretariado, necessário para o pensamento crítico acerca da profissão. Por esse motivo, os alunos dos semestres $1^{\circ}$ ao $4^{\circ}$ não compõemo universo da pesquisa;

c) Egressos - Os 35 Secretários Executivos que concluíram o curso nos últimos dois anos, sendo nove em 2014.1, 10 em 2014.2, 2 em 2015.1 e 14 sujeitos em 2015.2.

Da amostra selecionada, equivalente a 109 sujeitos, foram obtidos 53 retornos ao questionário, sendo que 11 foram invalidados porque suas respostas demonstraram que estavam em situação diferente daquela identificada como sendo a do público-alvo da pesquisa, totalizando então 42 respostas válidas. Quanto aos sujeitos respondentes, foram cinco professores, 23 estudantes e 14 egressos do curso de Secretariado Executivo da UFC, representando, respectivamente, $71 \%, 34 \%$ e $40 \%$ da população. A análise de conteúdo foi a técnica utilizada para a compreensão do material coletado, seguindo as etapas orientadas por Bardin (1977): pré-análise, exploração e interpretação.

\section{APRESENTAÇÃO E ANÁLISE DOS RESULTADOS}

Antes da análise dos dados propriamente dita, torna-se necessário fazer uma apresentação do perfil dos sujeitos da pesquisa, professores, estudantes e egressos. O corpo docente participante desta pesquisa é todo do sexo feminino, quatro professoras têm mais de 37 anos e uma está na faixa etária de 32 a 36 anos. Das cinco respondentes, duas indicaram que são mestras e três são doutorandas, sendo que três delas mencionaram ter como formação base o Secretariado Executivo. Quanto aos estudantes, 20 são do sexo feminino e apenas três são do sexo masculino. A maioria (65\%) está abaixo de 31 anos, com concentração na faixa etária de 22 a 26 anos. Dos 23 sujeitos apenas três já têm uma graduação anterior e um tem especialização completa, seis estudam no quinto semestre, 12 no sétimo e cinco no nono. Já em relação aos egressos, apenas três são do sexo masculino e os demais (11) são do sexo feminino. Semelhante ao perfil dos estudantes, a maioria (60\%) tem até 31 anos, estando a metade na faixa etária de 22 a 26 anos. Além da graduação em Secretariado Executivo, três são especialistas, dois estão cursando especialização e um está cursando mestrado. Em seguida serão apresentados os resultados pertinentes ao tema desta pesquisa.

\subsection{Formação do secretário executivo}

Para analisar a percepção que professores, estudantes e egressos do curso de Secretariado Executivo da UFC têm acerca da consultoria empresarial, estes foram questionados na pergunta 1 se concordam que o profissional de Secretariado Executivo, por sua formação multidisciplinar, está apto a seguir carreira em consultoria empresarial. De acordo com as respostas de todos os sujeitos foi possível perceber que $79 \%$ ou 33 respondentes, demonstram concordar que o Secretário Executivo está apto a seguir carreira em consultoria empresarial. A pergunta 7 está alinhada a estas informações, pois ela questiona 
se os sujeitos consideram que a formação oferecida aos estudantes do curso de Secretariado Executivo da UFC é suficiente para atuação destes como consultor empresarial. Percebe-se que entre as três categorias de respondentes da pesquisa a resposta negativa foi predominante, ao todo, $78 \%$ indicaram que para atuação em consultoria a formação oferecida no curso não é suficiente. Os principais motivos indicados pelos respondentes, em ordem decrescente de frequência, foram que: a) é necessária maior formação, complementar e aprofundada, o curso oferece apenas a base; b) falta aprofundamento do conteúdo visto e estudo de disciplinas específicas; c) falta experiência prática na área de consultoria; e, em menor frequência, d) o curso não tem como foco a formação em consultoria, esta não faz parte do seu perfil e do perfil do profissional.

Percebe-se que tanto na primeira quanto na sétima questão, independente da concordância, os respondentes mencionaram a necessidade de uma formação complementar à graduação, logo, para atuar em consultoria empresarial, a formação dada na graduação não é suficiente na opinião dos sujeitos participantes da pesquisa. Visto isso, é importante retomar o que Oliveira (2012) argumenta sobre a formação do consultor empresarial. Segundo esse autor, o plano de carreira para atuar na profissão de consultor empresarial está embasado no tripé: sustentação conceitual, experiência com foco de atuação e publicações com apresentações. Destaque para a sustentação conceitual, que se refere essencialmente à formação do profissional, que deve ser composta por um bom curso de graduação e, preferencialmente, por um curso de pós-graduação na área de atuação em consultoria. Portanto, apesar de ser verificado, de acordo com os respondentes da pesquisa e com o referencial teórico, que o profissional bacharel em Secretariado está apto a seguir carreira em consultoria empresarial, é necessária uma complementação da sua formação, seja por especialização, MBA, mestrado e/ou outras.

\subsection{Formação técnica e comportamental para consultoria}

Considerando os conhecimentos técnicos necessários para a atuação em consultoria, buscou-se identificar através dos respondentes, se a formação proporcionada ao estudante do curso de Secretariado Executivo da UFC abrange tais conhecimentos, preparando o profissional para atuar como consultor empresarial. Assim, a pergunta 3 do questionário buscou saber se, com base na estrutura curricular do curso, os respondentes concordam que o estudante adquire conhecimentos técnicos suficientes em determinadas áreas para prestar consultoria.

Como foi observado anteriormente, a graduação por si só não prepara o profissional para exercer plenamente a consultoria, logo conclui-se que os conhecimentos desenvolvidos nas áreas citadas na questão acima servem como base para o exercício da profissão de consultor, sendo insuficientes para a atuação profissional.

Dessa forma, percebe-se que, segundo os respondentes, existem algumas áreas nas quais o profissional desenvolve mais conhecimentos durante a graduação do que em outras. Essas, por ordem decrescente de frequência, são: desenvolvimento organizacional ( $83 \%$ ou 35 respondentes), gestão de pessoas (81\%), processos (76\%) e estratégia (64\%). Portanto, podese inferir que em tais áreas o Secretário Executivo tem maior aptidão e embasamento para prestar consultoria, desde que aprofunde seus conhecimentos. Ao contrário, nas áreas de produção (69\%), finanças (67\%), logística (57\%) e marketing (48\%), o profissional pode necessitar de maior embasamento para prestar consultoria, uma vez que apresentam, na visão dos sujeitos da pesquisa, menor desenvolvimento durante a graduação.

Os conhecimentos mencionados acima estão relacionados com o que Block (2011) denomina habilidades técnicas. Segundo o autor, as habilidades técnicas se referem à experiência do consultor em determinado campo de atuação, como marketing, planejamento, 
engenharia, finanças, gestão de projetos etc. A maioria dos comentários acrescentados à questão anterior concordam que o curso oferece uma formação multidisciplinar, mas o conteúdo estudado não é suficiente para a atuação em consultoria. Apenas quatro respondentes indicaram que o profissional está apto a atuar em qualquer uma das áreas listadas na pergunta 3. Com isso, é necessário entender quais conhecimentos são mais desenvolvidos durante a graduação do profissional de Secretariado Executivo, de forma que este possa aprofundar tais conhecimentos futuramente e adquirir as competências necessárias para uma atuação plena em consultoria empresarial.

$\mathrm{Na}$ pergunta 5 buscou-se entender quais as competências mais desenvolvidas nos estudantes do curso de Secretariado Executivo durante a graduação, de forma que se possa avaliar a proximidade com o perfil de um consultor.

Pelos dados obtidos, foi possível perceber que as competências mais desenvolvidas durante a graduação foram, de acordo com a frequência: suporte, trabalho em equipe, relacionamento interpessoal e saber ouvir. A competência que foi mais indicada como pouco desenvolvida ou não desenvolvida foi a análise de dados. A esta, por ordem decrescente de frequência, segue negociação, tomada de decisão, confronto, assertividade e planejamento, apontadas como menos desenvolvidas.

Logo, percebe-se que todas as competências listadas na pergunta são adquiridas pelos estudantes de graduação, algumas delas em maior ou menor intensidade, de acordo com o perfil do curso e do próprio aluno. Sobre esse aspecto é importante retomar os argumentos de Durante (2012), quando aponta que os conhecimentos, habilidades e atitudes inerentes ao perfil secretarial são complementares e podem se manifestar em maior ou menor grau em cada indivíduo, a depender de sua área de atuação ou posição dentro da organização.

Do ponto de vista das professoras, nenhuma das competências foi indicada como não desenvolvida. As maiores variações nas respostas se encontram entre estudantes e egressos. É possível verificar, ao analisar as respostas dos sujeitos da pesquisa, que a listagem feita por Durante (2012) dos conhecimentos, habilidades e atitudes desenvolvidas no profissional de Secretariado Executivo estão presentes no decorrer da graduação dos estudantes do curso. Além disso, tem relevância também a constatação de que as competências listadas por Block (2011) como necessárias ao consultor estão condizentes com o perfil construído no Secretário Executivo, o que o aproxima mais ainda da consultoria empresarial.

\subsection{Carreira em consultoria empresarial segundo os respondentes}

Para analisar os aspectos inerentes à carreira em consultoria, na pergunta 9, direcionada aos estudantes e egressos, foi questionado se os respondentes consideravam atuar profissionalmente como consultores. Apenas quatro dos 37 sujeitos afirmaram que desejam atuar em consultoria, sendo três estudantes e um egresso. Todos os demais não pretendem. Apesar disso, 27 consideram que a consultoria é uma opção de carreira ao profissional de Secretariado Executivo, 17 estudantes e 10 egressos. Seis respondentes não consideram e nenhum dos sujeitos afirmou já atuar como consultor.

Essa informação mostra que tanto estudantes quanto egressos, em sua maioria, têm uma visão positiva acerca da atuação do Secretário Executivo enquanto consultor. Entretanto o interesse em seguir carreira em consultoria empresarial ainda é mínimo. Essa informação corrobora com o os argumentos de Schmitz et al. (2015, p. 22), quando citam que "embora esse profissional seja visto como um ser dinâmico e versátil, ou seja, um profissional que se sobressai em diversos setores abrangentes ao seu perfil, ainda é pouco associado ao serviço de consultoria".

$\mathrm{O}$ fato de apenas quatro respondentes afirmarem desejar atuar em consultoria tem relação direta com os dados coletados na pergunta 10, também direcionada aos estudantes e 
egressos. Os sujeitos foram questionados se durante a graduação foram estimulados a aprofundar os conhecimentos em consultoria empresarial e a seguir carreira nessa área. A maioria, 22 dos 37 sujeitos, informou não ter sentido esse estímulo. Apenas 13 informaram ter sido estimulados para a consultoria, e dois não souberam ou não puderam responder. Houve um equilibrio entre os respondentes que não concordam em ter recebido citado estímulo, pois 11 são estudantes e 11 são egressos. Entre os que concordam que se sentiram estimulados, 10 são estudantes e apenas três são egressos. É possível observar maior disparidade entre aqueles sujeitos que já concluíram o curso, pois $76 \%$ indicaram que não sentiram estímulo no direcionamento de sua carreira para consultoria empresarial durante a graduação. Ainda sobre esse aspecto é importante observar os dados revelados pela pergunta 8, que mostra que a maioria dos sujeitos da pesquisa (64\% ou 27 respondentes), principalmente estudantes e egressos, ainda não tiveram nenhum contato com consultoria empresarial.

Essa falta de contato com a consultoria empresarial durante a graduação, ou até mesmo após, no caso dos egressos, bem como o não conhecimento de profissionais consultores que sirvam de referência (realidade de 17 dos 42 respondentes), inevitavelmente, influencia no interesse dos estudantes e egressos pela carreira na área. Logo, cabe ao curso de graduação apresentar todas as possibilidades de carreira do Secretário Executivo durante sua graduação, de forma que ele possa direcionar seu desenvolvimento profissional de acordo com suas aptidões, sua formação e a necessidade do mercado.

É possível verificar, portanto, a importância do papel do curso de graduação em Secretariado Executivo na orientação ao estudante quanto às suas opções de carreira e, dessa forma, abordar a consultoria empresarial nessa discussão, de modo a que o estudante esteja atento às possibilidades para sua atuação profissional.

Sobre a atratividade do mercado de consultoria no Ceará para o profissional de secretariado, questão formulada especificamente aos professores, as respostas foram unânimes em afirmar que há a percepção de oportunidade para a atuação do Secretário Executivo.

Foi possível perceber ainda que apenas 10 respondentes já prestaram consultoria. Desses, quatro são professoras e seis são estudantes, apesar destes terem indicado que atualmente não atuam como consultores. Entre as professoras, duas são mestres e três são doutorandas.

\section{CONSIDERAÇÕES FINAIS}

Ao analisar a percepção dos sujeitos desta pesquisa, constatou-se que o Secretário Executivo considera a consultoria empresarial como uma opção de carreira ao profissional formado em Secretariado, o que responde ao objetivo geral deste trabalho. Atendendo ao primeiro objetivo específico, foi verificado que na percepção da maioria dos respondentes há uma concordância de que, em razão da sua formação multidisciplinar, o Secretário Executivo está apto a seguir carreira em consultoria, principalmente em desenvolvimento organizacional, gestão de pessoas, processos e estratégia. Entretanto, para a atuação como consultor, somente o curso de graduação não é suficiente, é necessário um aprofundamento de seus conhecimentos, posterior à graduação, pois a formação dada nesse nível não prepara o estudante para prestar consultoria.

Outro aspecto analisado foi o interesse dos estudantes e egressos do curso de Secretariado Executivo da UFC em seguir carreira na área de consultoria empresarial, atendendo ao segundo objetivo específico desta pesquisa. Pela análise dos dados coletados, esse interesse ainda é mínimo. Isso pode ser explicado por dois motivos: o primeiro é o pouco estímulo oferecido aos estudantes e o segundo é o reduzido contato com a consultoria empresarial durante a graduação. 
Quanto ao terceiro objetivo específico, conclui-se que o curso oferece as bases conceituais para o estudante que deseja seguir carreira nessa área poder se aprofundar, por meio de cursos específicos à área em que pretende trabalhar. Além da formação técnica, o curso também contribui para a formação social e humana dos estudantes, principalmente no que diz respeito às relações interpessoais. Entre as competências listadas para os respondentes da pesquisa, todas foram indicadas como desenvolvidas durante a graduação, em maior ou menor intensidade. As principais foram suporte, trabalho em equipe, relacionamento interpessoal e saber ouvir. A relevância dessas constatações está em verificar que para o perfil do consultor, além das competências técnicas, de especialização, que são necessárias, as competências humanas também são indispensáveis para o exercício da profissão, principalmente o relacionamento interpessoal. Dessa forma, percebe-se neste tema proximidade entre o perfil necessário ao consultor e o perfil do secretário executivo. Portanto, do ponto de vista de formação básica, a consultoria empresarial é uma área promissora ao Secretário Executivo.

Por fim, este estudo torna-se relevante à área de Secretariado na medida em que revela informações a serem consideradas pelos alunos sobre as diferentes áreas em que pode atuar, bem como aprofundar seus conhecimentos em consultoria empresarial. Da mesma forma, para que os cursos de graduação em Secretariado abordem, por meio da sua estrutura curricular e corpo docente, essas opções de carreira durante a graduação, de modo que aumente as possibilidades do Secretário Executivo de atuar em áreas antes pouco exploradas por este profissional. As principais limitações do artigo se encontram na limitação de acesso aos sujeitos, o que reduz o volume de respostas, dificultando a generalização dos resultados. Para pesquisas futuras sugere-se a inclusão do estudo do mercado de consultoria para identificar se o profissional de secretariado está atuando nessa área.

\section{REFERENCIAS}

Adelino, F. J. S. \& Silva, M. A. V. (2012). A tecnologia da informação como agente de mudança no perfil do profissional de secretariado. Revista de Gestão e Secretariado, 3(2), 5-23. Recuperado em 21 junho, 2016, de https://www.revistagesec.org.br/secretariado/article/view/165/pdf_20

Andrade, M. M. (2009). Introdução à metodologia do trabalho científico: elaboração de trabalhos na graduação (9a ed.). São Paulo: Atlas.

. (2010). Introdução à metodologia do trabalho científico: elaboração de trabalhos na graduação (10a ed.). São Paulo: Atlas.

Bardin, L. (1977). Análise de conteúdo. Lisboa: Edições 70.

Block, P. (2011). Flawless consulting: A guide to get your expertise used (3a ed.). San Francisco: Pfeiffer.

Brasil. (2005). Ministério da Educação, Conselho Nacional de Educação. Resolução n ${ }^{\circ}$ 3, de 23 de junho de 2005. Diretrizes Curriculares Nacionais para o curso de graduação em Secretariado Executivo. Brasilia, DF. Recuperado em 21 junho, 2016, de http://portal.mec.gov.br/cne/arquivos/pdf/rces003_05.pdf.

Coelho, J. (2013). Diário de um consultor: a consultoria sem segredos. São Paulo: Atlas. 
Crocco, L. \& Guttmann, E. (2010). Consultoria empresarial (2a ed.). São Paulo: Saraiva.

Donadone, J. C. \& Sznelwar, L. I. (2004). Dinâmica organizacional, crescimento das consultorias e mudanças nos conteúdos gerenciais nos anos 90. Revista Produção 14(2). Recuperado em 21 junho, 2016, de http://www.scielo.br/scielo.php?script=sci_arttext\&pid=S0103-65132004000200006

Durante, D. G. (2012). Tópicos especiais em técnicas de Secretariado. Curitiba: Iesde Brasil S.A.

Laboratório, C. (2015). Perfil das empresas de consultoria no Brasil 2014. Recuperado em 25 junho, 2016, de http//laboratoriodaconsultoria.com.br/site/wpcontent/uploads/2015/01/Perfil-das-Empresas-de-Consultoria-no-Brasil-outubro2014.pdf

Marconi, M. A. \& Lakatos, E. M. (2003). Fundamentos de metodologia científica (5a ed.). São Paulo: Atlas. . (2010). Fundamentos de metodologia científica (7a ed.). São Paulo: Atlas.

Martins, C. B.; Terra, P. M.; Maccari, E. \& Vicente, I. (2010). A formação do profissional em secretariado executivo no mercado de trabalho globalizado. Revista de Gestão e Secretariado 1(1). Recuperado em 21 junho, 2016, de https://www.re vistagesec.org.br/secretariado/article/view/4/73

Martins, C. B.; Terra, P. M.; Kiehn, M. \& Kniess, C. T. (2015). Formação em consultoria organizacional: uma análise prática. Revista Capital Científico 13(3). Recuperado em $21 \quad$ junho, 2016, de http://revistas. unicentro.br/index.php/capitalcientifico/article/view/3073/2746

Martins, G. A. \& Theóphilo, C. R. (2009). Metodologia da investigação científica para ciências sociais aplicadas (2a ed). São Paulo: Atlas.

Neiva, E. G. \& D’Elia, M. E. S. (2009). As novas competências do profissional de Secretariado (2a ed.). São Paulo: IOB Folhamatic.

Nonato Júnior, R. (2009). Epistemologia e teoria do conhecimento em Secretariado Executivo: a fundação das ciências da assessoria. Fortaleza: Expressão Gráfica.

Oliveira, D. P. R. (2012). Manual de consultoria empresarial: conceitos, metodologia, práticas (11a ed.). São Paulo: Atlas.

Paes, R. V. O.; Antunes, C. K. S.; Santiago, C. S. \& Zwierzikowski, M. R. (2015). Novas formas de atuação do profissional de secretariado executivo. Revista de Gestão e Secretariado 6(1). Recuperado em 21 junho, 2016, de https://www.revistagesec.org.br/secretariado/article/view/318/pdf_64

Rodrigues, A. J. (2006). Metodologia científica. São Paulo: Avercamp. 
Schein, E. (2008). Princípios da consultoria de processos: para construir relações que transformam. São Paulo: Instituto Fonte para o Desenvolvimento Social.

Schmitz, C. J.; Battisti, P. S. S. \& Santos, S. R. F. (2015). Uma análise da consultoria secretarial como novo nicho de mercado e como disciplina nos cursos de secretariado executivo. Revista de Gestão e Secretariado 6(2). Recuperado em 21 junho, 2016, de https://www.revistagesec.org.br/secretariado/article/view/272/pdf_69

Silva, A. C. B. R. (2010, novembro). Atuação e competências do secretário executivo: assessor, gestor, consultor, empreendedor. Anais do Encontro Nacional Acadêmico de Secretariado Executivo, Toledo, PA, Brasil. Recuperado em 21 de junho, 2016, em http://www.abpsec.com.br/abpsec/index.php/i-enasec-apresentacao 